\title{
PROCESSO ELETRÔNICO DE APROVEITAMENTO DE ATIVIDADES COMPLEMENTARES: PROPOSTA DE CRIAÇÃO NUMA IES
}

http://dx.doi.org/10.5902/2318133842365

\author{
Erickson Santos de Alcântara ${ }^{1}$ \\ Maria Conceição Melo Silva Luft ${ }^{2}$ \\ Thais Ettinger Oliveira Salgado 3 \\ Kleber Fernandes de Oliveira ${ }^{4}$
}

\begin{abstract}
Resumo
A transição dos processos físicos para os processos eletrônicos procura beneficiar as organizações públicas, proporcionando benefícios para a gestão. Nesse sentido, o objetivo deste artigo foi elaborar uma proposta de criação do sistema de processo eletrônico de aproveitamento de atividades complementares numa instituição de ensino superior brasileira. O estudo utilizou como fonte de evidências a observação participante e a análise documental. O sistema proposto está em fase de teste do protótipo e experiências nele realizadas sugerem melhora significativa na gestão do processo.

Palavras-chave: administração pública; atividades complementares; e-acadêmico.
\end{abstract}

\section{ELECTRONIC PROCESS FOR ADVANCING COMPLEMENTARY ACTIVITIES: PROPOSAL OF CREATION IN A HIGHER EDUCATION INSTITUTION}

\begin{abstract}
The transition from physical to electronic processes seeks to benefit public organizations, providing benefits for management. In this sense, the objective of this article was to elaborate a proposal for the creation of the electronic process system to take advantage of complementary activities in a brazilian higher education institution. The study used participant observation and documentary analysis as a source of evidence. The proposed system is in the test phase of the prototype, and experiments carried out on it suggest a significant improvement in the management of the process. Key-words: public administration; additional activities; e-academic.
\end{abstract}

\footnotetext{
1 Universidade Federal de Sergipe, Brasil. E-mail: erickson@ufs.br.

2 Universidade Federal de Sergipe, Brasil. E-mail: ceica@infonet.com.br.

3 Universidade Federal de Sergipe, Brasil. E-mail: thaisettufs@gmail.com.

4 Universidade Federal de Sergipe, Brasil. E-mail: kleber.ufs@hotmail.com.
} 


\section{Introdução}

erviço público, em sentido amplo, é todo aquele prestado pela administração

1 ou por seus delegados, sob normas e controles estatais, para satisfazer necessidades essenciais ou secundárias da coletividade, ou simples conveniências do Estado (Meirelles, 2010).

O uso da tecnologia na gestão das organizações públicas mostra-se a cada ano uma realidade presente e necessária, de modo que a utilização de tecnologia da informação e comunicação, principalmente a partir da informatização de procedimentos e da facilitação da comunicação, tem promovido estruturas governamentais inteligentes, sustentáveis e inovadoras (European Commission, 2010).

$\mathrm{Na}$ busca constante por ganhos de eficiência, a administração pública tem considerado alternativas para modernizar a sua gestão. Dentre elas a transição de processos físicos para processos eletrônicos, com a redução do uso de recursos com materiais, pessoal e com tempo na administração pública (Moraes, 2016).

No Brasil, o governo federal autorizou, por meio do decreto n. 8.917/2015 (Brasil, 2015), o uso do meio eletrônico para a realização do processo administrativo na administração pública federal com o objetivo de: assegurar a eficiência, a eficácia e a efetividade da ação governamental e promover a adequação entre meios, ações, impactos e resultados; promover a utilização de meios eletrônicos para a realização dos processos administrativos com segurança, transparência e economicidade; ampliar a sustentabilidade ambiental com o uso da tecnologia da informação e da comunicação e facilitar o acesso do cidadão às instâncias administrativas.

O processo administrativo eletrônico consiste na criação de processos completamente digitais sem a necessidade de uso de papéis e impressões a partir de um sistema informatizado com participação de diversos atores, como administrador, funcionário/servidor, cliente/cidadão, etc. Por meio do processo eletrônico é possível realizar operações de tramitações, de despachos e encaminhamentos e de consultas inteiramente via sistema.

Diante deste cenário, e considerando a experiência de servidores públicos efetivos de uma instituição federal de ensino superior, apresenta-se uma proposta de criação de processo acadêmico eletrônico, especificamente de atividades complementares, no Departamento de Computação da Universidade Federal de Sergipe - UFS -, com intuito de beneficiar os usuários desse serviço na instituição.

A proposta justifica-se por contribuir com o aprimoramento da gestão de processos acadêmicos de uma instituição de ensino superior, prática benéfica aos demais órgãos que a ela aderiram, visando, principalmente, ao auxílio na gestão dos processos nas unidades acadêmicas, bem como ao aumento da celeridade na conclusão dos processos, à possibilidade de acompanhamento real das análises em quaisquer lugar e tempo e à economia de recursos públicos.

Ademais, a partir da implantação de um sistema voltado para atender a dificuldades de procedimentos de um departamento acadêmico, também é possível melhorar a gestão e controle de documentos em setores de base da instituição, devendo, assim, contribuir essencial e diretamente com o atendimento a grande parte da comunidade acadêmica. 


\section{Processo administrativo e informatização de documentos}

Processo administrativo é uma sucessão itinerária e encadeada de atos administrativos que tendem a um resultado final e conclusivo. Isso significa que para existir o processo, cumpre que haja uma sequência de atos conectados entre si, isto é, armados em uma ordenada sucessão visando a um ato derradeiro (Mello, 2015).

Para Cunha Júnior (2016) existe a dualidade entre os processos internos, ou técnicos, que são aqueles que se desenvolvem na intimidade da administração, visando à prática de um ato de expediente ou de um fato administrativo; e os processos externos, ou jurídicos, dos quais participam os cidadãos-administrados, voltados a produzir algum ato ou decisão que repercutirá na esfera jurídica de terceiros - ressalta-se que os processos acadêmicos se apresentam como processos externos, incluindo o de Atividades Complementares.

Segundo Carvalho Filho (2015) os processos administrativos podem ser classificados em dois grandes grupos: os processos não litigiosos, que são aqueles em que não se apresenta conflito de interesses entre o Estado e um particular, ou seja, aqueles que têm por objetivo somente a apuração de um fato, como o inquérito policial, o inquérito civil ou a sindicância administrativa - e nessa classificação está inserida a maioria dos processos acadêmicos; e os processos litigiosos, que são aqueles que contêm de fato um conflito de interesses entre o Estado e o administrado, isto é, aqueles que percorrem diversas instâncias administrativas formadas de agentes e de órgãos administrativos, como os tribunais e conselhos administrativos, aos quais compete decidir sobre as controvérsias.

Para Di Pietro (2010) o processo administrativo pode ser classificado em dois tipos: o gracioso e o contencioso. O processo administrativo gracioso é aquele em que a administração está encarregada de fazer atuar a vontade concreta da lei, enquanto o processo administrativo contencioso é o que se desenvolve perante um órgão independente e imparcial, com competência para decidir sobre as questões surgidas entre administração e administrado.

Na maioria das instituições públicas grande parte de suas informações se encontra em documentos textuais, das quais, na ausência da gestão documental e de mão de obra qualificada, a maioria é armazenada de forma incorreta e sem critérios definidos, perdendo rapidamente seu valor para a instituição (Felix; Silva, 2010).

Diante do crescente uso de ferramentas de TIC, toda e qualquer organização, independentemente de sua atividade fim, produz e demanda documentos em formato impresso ou digital, que necessitam ser gerenciados de forma eficaz (Silva; Portugal, 2016). Sistemas de informação e ferramentas tecnológicas são desenvolvidos como suporte para o tratamento da informação, e as organizações, cada vez mais, carecem de adotar políticas de gestão documental (Elias, 2012).

Pérez (2001) já destacava a importância da gestão de documentos como ferramenta de suporte à gestão do conhecimento, ao definir que "o conhecimento não é uma entidade física tangível, gestão do conhecimento não é realmente o produto, mas um processo, uma maneira de relacionar as informações e experiência" (p. 193). O autor ressalta o gerenciamento eletrônico de documentos como um processo que busca atender às novas necessidades das organizações de melhor gerenciamento de suas informações e aprimoramento da gestão do conhecimento (Silva; Portugal, 2016). 
A combinação de novas tecnologias, especificações abertas, arquiteturas inovadoras e a disponibilidade de informações do setor público podem proporcionar maior valor aos cidadãos com menos recursos (European Commission, 2010). Ribeiro (2010) afirma que a "gestão documental significa a sobrevivência, a competitividade de uma instituição; conduz à transparência das atividades, possibilitando a governança e o controle das informações" (p. 65).

Diante do que foi exposto, entende-se que apenas dispor da informação não é suficiente. É preciso saber organizá-la e utilizá-la da melhor maneira possível para proporcionar maior segurança, agilidade e assertividade nos processos administrativos.

\section{Processo eletrônico no Brasil}

O uso de processos e documentos eletrônicos tem sido intensificado em diversos setores da administração pública. A política de governo eletrônico brasileira, pertinente ao andamento de melhoria da gestão interna, tem como objetivo dinamizar a prestação de serviços públicos com foco na eficiência e efetividade das funções governamentais; aprimorar a qualidade dos serviços prestados, bem como e fortalecer a participação cidadã por meio do acesso a informação e a uma administração mais eficiente (Corrêa, 2011).

A introdução da imagem digital como um documento válido representa uma mudança cultural capaz de alterar conceitos administrativos e operacionais que conduzam a relação entre Estado e sociedade para um ambiente de maior interação e democracia, no qual o ato administrativo é publicado em um processo digital acessível via Internet. A ideia de ter um processo digital reforça os conceitos de responsabilidade e compromisso, já que propicia a transparência e a rastreabilidade do ato público (Enap, 2012).

Nesse contexto, o processo administrativo eletrônico, substituição do meio físico pelos meios de armazenamento disponibilizados pela informática, possibilita 0 desenvolvimento da atividade administrativa de modo mais eficaz, mediante a automação de rotinas e atos processuais (Corrêa, 2011). As principais vantagens que se pode sinalizar para essa transição dizem respeito aos seguintes tópicos: a) encerramento do processo em papel; b) agilidade na tramitação; c) custo-benefício do procedimento; d) tráfego e trânsito do informe, sem congestionamento; e) redução do número de incidentes; f) redução do custo de transporte e deslocamento de Pessoal (Abrão, 2013).

Dentre os benefícios propiciados pela utilização de autos processuais digitais, merecem destaque a economia de recursos públicos com insumos, assim como a formação e tramitação de processos em meio virtual demanda um número menor de servidores do que o necessário no modelo tradicional, em decorrência da automação de atividades antes realizadas por pessoas, permitindo o aproveitamento de servidores antes encarregados de rotinas burocráticas suprimidas ou minimizadas pelo processamento eletrônico - em outras áreas do órgão (Corrêa, 2011).

Essa automação de rotinas é apontada como a razão principal da celeridade e eficiência obtidas com a implantação do processo eletrônico, pois essa nova tecnologia permite a realização de tramitação e acesso aos autos e documentos a qualquer momento por meio eletrônico, com consequente redução de tempo. 
A transformação dos processos em papel em processos digitais eletrônicos não somente abre espaço para uma revolução procedimental, mas, sobretudo, introduz uma nova cultura gerencial pela qualidade. Desse modo, no intuito de garantir essa evolução gerencial de modo prático, apresentam-se, a seguir, os procedimentos metodológicos para a proposta de criação do Processo Acadêmico Eletrônico - e-Acadêmico - numa instituição de ensino superior.

\section{Procedimentos metodológicos}

Este trabalho pode ser caracterizado como exploratório, considerando a busca por mais informações acerca do tema e a procura por maior familiaridade com o problema, e explicativo, uma vez que seu resultado visa à solução para um problema prático, aproximando o estudo do conhecimento efetivo da realidade.

Com finalidade de atingir o objetivo do estudo foram utilizadas como fonte de evidências a observação e a análise documental, consideradas formas apropriadas para o tipo de pesquisa. A análise documental ocorreu mediante consulta a modelos de requerimento para solicitação de abertura de processo, a normas e resoluções que regem o procedimento de aproveitamento de atividades complementares, a relatórios de processos analisados pela unidade focal da pesquisa, que contempla três cursos de graduação: bacharelado em Ciência da Computação, bacharelado em Engenharia de Computação e bacharelado em Sistemas de Informação, cujo número de alunos ativos é de 455, 266 e 243, respectivamente (UFS, 2017). A observação, por sua vez, foi participante, em que os autores se incorporaram à situação-problema pertencendo ao grupo investigado.

No intuito de adequar-se ao contexto do estudo, que visa a explorar um fenômeno procedimento de aproveitamento de atividades complementares - e criar e explicar um novo, benefícios e limitações, foi desenvolvido o protocolo da pesquisa.

Figura 1 -

Protocolo da pesquisa.

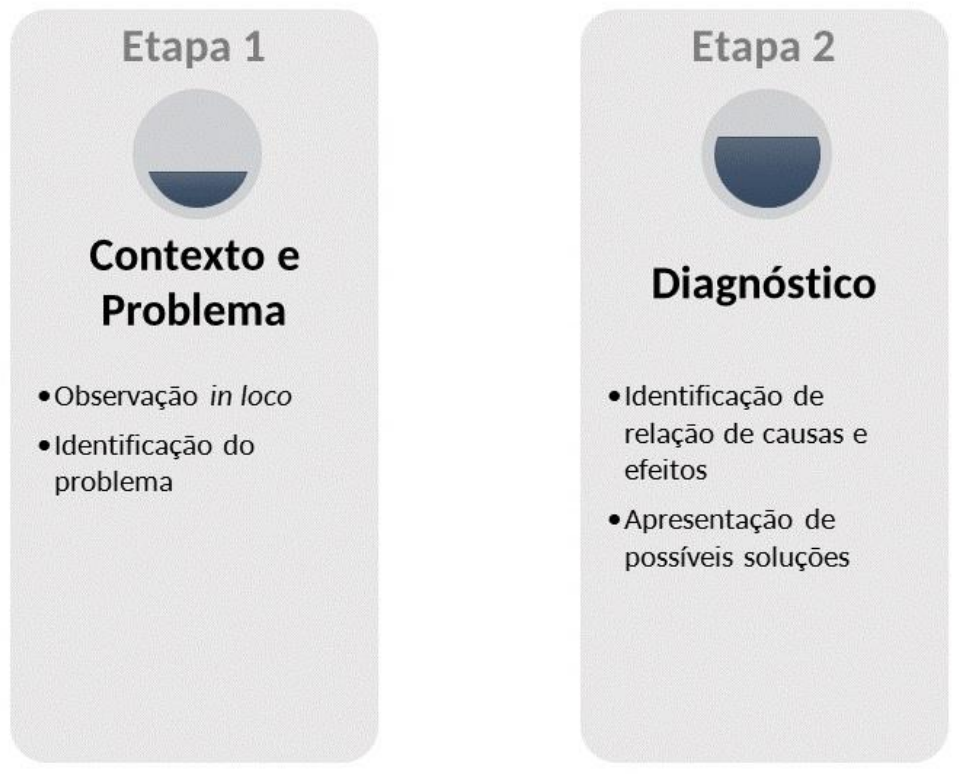

Etapa 3

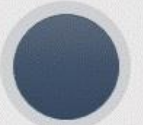

Planejamento e Intervenção

- Proposta de projeto de melhoria

- Planejamento de intervençāo 
A Universidade Federal de Sergipe - UFS - é composta por seis campi distribuídos em: a cidade universitária, localizada na cidade de São Cristóvão e principal campus da instituição; o campus de Aracaju, localizado na capital do Estado e composto principalmente pelo Hospital Universitário; o campus de Itabaiana, localizado na região agreste do Estado e o primeiro fora da região metropolitana da capital; o campus de Laranjeiras, composto por cursos de afinidades artísticas, culturais e históricas; o campus de Lagarto, formado por cursos de especialidades na área de saúde; e o campus do Sertão, localizado no município de Nossa Senhora da Glória, no Alto Sertão Sergipano.

Considerando que a existência de atividades complementares como componente curricular é obrigatória em todos os cursos de graduação (UFS, 2015), a solicitação de aproveitamento de atividades complementares é comum a grande parte dos alunos de graduação, sendo realizada e registrada na evolução curricular do discente por meio de processo acadêmico.

Nesse contexto, na etapa 1, a partir da observação in loco, foi possível detectar que a unidade focal da pesquisa apresentou, por vezes, dificuldades no gerenciamento de alguns desses processos, acarretando prejuízos não somente ao interessado do processo, como também à própria organização. Desse modo, a pesquisa teve como pretensão contribuir para uma análise célere, eficaz e padronizada dos processos de atividades complementares.

A etapa 2 objetivou identificar possíveis relações de causas e efeitos, bem como apresentar prováveis soluções para a resolução da situação diagnosticada. Utilizando-se do Diagrama Ishikawa, a figura 2 expõe as principais causas para o atraso nas análises do processo.

Figura 2 -

Diagrama Ishikawa de atraso no processo.

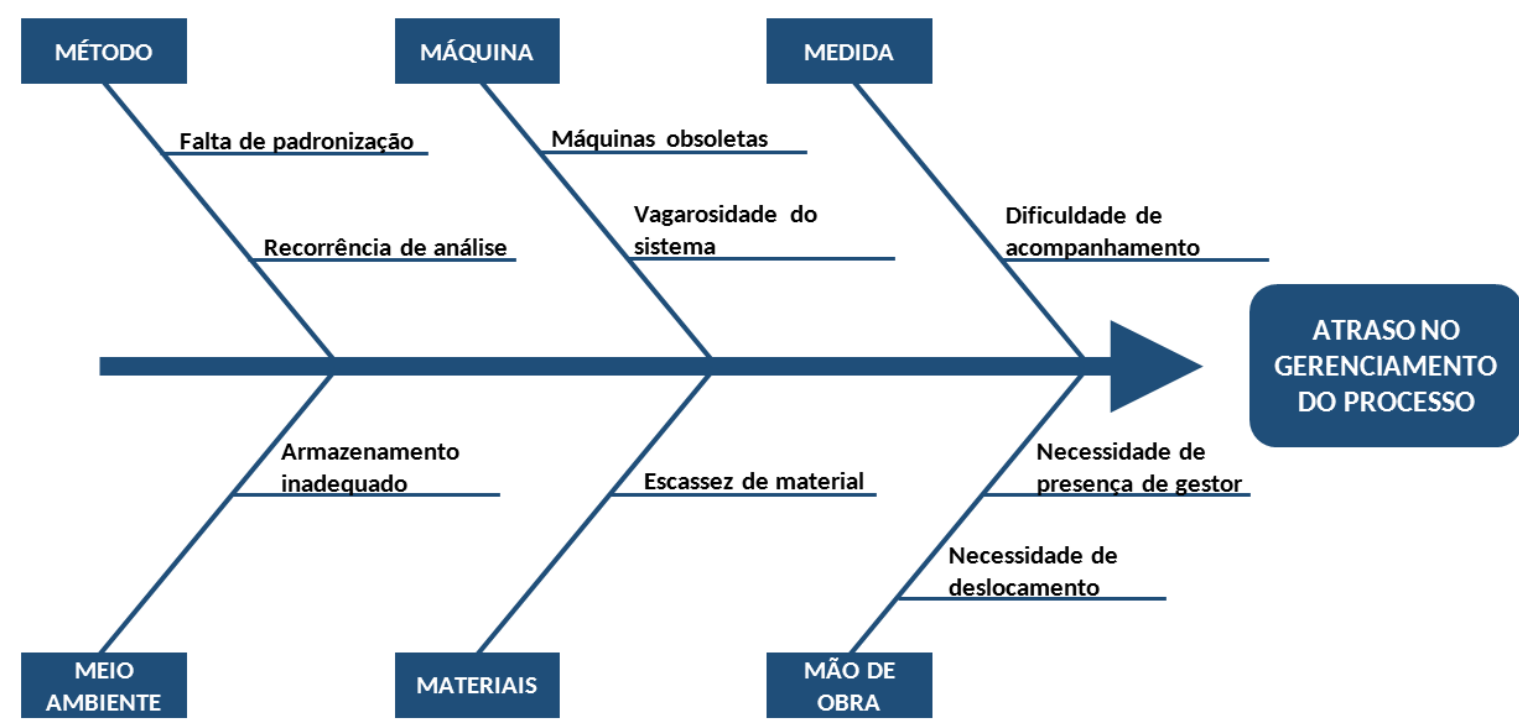

Fonte: autores (2019). 
Cumpre ressaltar que em outubro de 2017 a UFS implantou um módulo de processos eletrônicos por meio do Sistema Integrado de Patrimônio, Administração e Contratos - Sipac. Embora o cenário de gerenciamento de processos na instituição, com essa implantação, possa alcançar importantes melhorias, o processo eletrônico em uso ainda apresenta lacunas que precisam ser aperfeiçoadas de acordo com a necessidade de cada tipo de processo. Desse modo, ao analisar as informações do Diagrama de Ishikawa caracterizaram-se os procedimentos com processo físico, com processo eletrônico do Sipac e com processo eletrônico do e-Acadêmico.

Em relação ao método, no processo físico, a falta de padronização no procedimento de análise tornava-se recorrente, tanto entre gestões de cursos, quanto entre sucessivas gestões de um mesmo curso, já que não havia uma unidade formal de procedimento para tal ação. Ademais, pela complexidade de registros de análises já realizadas anteriormente, de modo a padronizar as concessões deferidas, a recorrência de análise de solicitações semelhantes era uma ocorrência comum no processo físico, demandando tempo replicado e podendo acarretar decisões divergentes entre as análises.

No processo eletrônico do Sipac essas dificuldades persistem para o processo de aproveitamento de atividades complementares pelo fato de o sistema em questão possuir funcionalidades genéricas englobando os diversos tipos de processos existentes na instituição. O e-Acadêmico, por ser elaborado com base nas resoluções acerca do procedimento, possibilitará mais facilmente um julgamento em conformidade com as normas, além de auxiliar na tomada de decisões a partir de registros e análises anteriores.

Quanto ao meio ambiente, o processo físico, em razão de permanecer retido na unidade no aguardo de análise, permanecia exposto à possibilidade de danificação dos autos ou ainda perda do processo. Soma-se a isso a escassez de recursos para o adequado armazenamento de documentos nos órgãos públicos. Com a implantação do processo eletrônico - Sipac e e-Acadêmico -, o armazenamento de processo transfere a exigência de investimento para equipamentos tecnológicos e elimina a necessidade de espaço físico para tal finalidade.

No tocante à máquina, tanto para o processo físico, quanto para os processos eletrônicos do Sipac e do e-Acadêmico, os equipamentos obsoletos e desatualizados oferecidos para o desenvolvimento das atividades laborais dificultam o bom seguimento dos processos. O processo físico - que necessitava da tramitação eletrônica entre setores no Sipac - e o processo eletrônico do Sipac lidam com a vagarosidade do sistema, acarretando o atraso no andamento dos processos da instituição.

Acerca de material, a partir da escassez de recursos cada vez mais presente nos órgãos do serviço público brasileiro, a despesa de material para composição de processo físico tinha um notável impacto financeiro nos recursos da universidade. A adesão ao processo eletrônico provoca naturalmente a redução de despesas com material de consumo.

Relacionado à medida, o processo físico dificultava ao interessado o acompanhamento dos autos do processo, com acesso aos encaminhamentos e decisões durante a tramitação do documento. O processo eletrônico do Sipac, apesar de informatizar todo o procedimento, não concede ao interessado 0 acesso para 
acompanhamento na plataforma eletrônica do teor dos respectivos encaminhamentos. Com o e-Acadêmico, o interessado poderá consultar a qualquer tempo o andamento do processo, observando em tempo real as análises da documentação.

Por fim, no tocante à mão de obra, o processo de natureza física demandava a presença do gestor da unidade para tramitação, o que protelava, por vezes, o andamento do processo. Somada a isso, a necessidade de deslocamento do processo físico entre unidades acarretava atraso na tramitação dos documentos. O processo eletrônico, seja do Sipac ou do e-Acadêmico, transforma essa realidade, possibilitando aos gestores dar prosseguimento ao processo a qualquer tempo e lugar.

A etapa 3 visou à elaboração do planejamento de ações para a proposta de intervenção da pesquisa a partir da criação do e-Acadêmico de aproveitamento de atividades complementares no Departamento de Computação da UFS. A proposta de intervenção do presente estudo desenvolve-se por meio do Portal Administrativo do Departamento de Computação, ferramenta de gestão da unidade que fornece gerenciamento de usuários; calendários dinâmicos para laboratórios, equipamentos e salas; sistema de reservas e controle; sistema de requerimentos; sistema de chamados de manutenção; suporte para e-mail institucional; controle de acessos e controle de sanidade de máquinas (Admindcomp, 2018).

\section{Análise e proposição: processos acadêmicos de atividades complementares}

$O$ processo de atividades complementares consiste no aproveitamento de um conjunto de estratégias didático-pedagógicas que permitem a articulação entre teoria e prática e a complementação dos saberes e habilidades necessárias, a serem desenvolvidas durante o período de formação do estudante (UFS, 2015). É por meio desse processo que os discentes efetivam o cumprimento das atividades extracurriculares como componente obrigatório e/ou optativo dos respectivos cursos.

Processo existente

Tanto no procedimento com documentação física, quanto com a implantação do processo eletrônico, o processo de aproveitamento de atividades complementares na instituição tem uma ocorrência de registros. Na figura 3 se ilustra os procedimentos adotados, em geral, para registro de atividades complementares na evolução curricular dos alunos de graduação, efetuado através de processo acadêmico - de natureza física e, mais recentemente, de forma eletrônica. 
Figura 3 -

Processo de aproveitamento de atividades complementares existente.

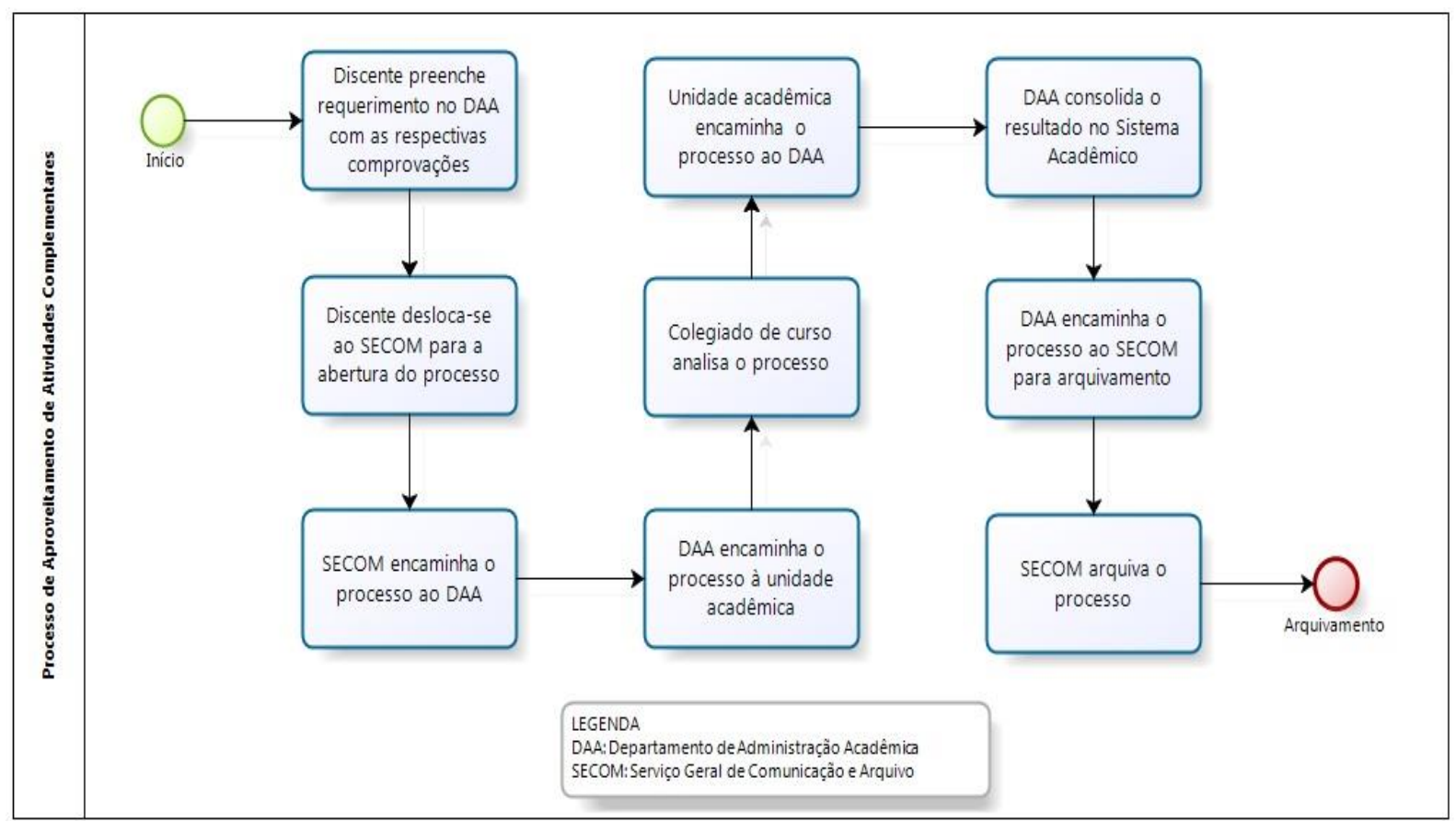

Fonte: autores (2019).

O interessado, como passo inicial para abertura do processo de aproveitamento de atividades complementares, dirige-se, com as respectivas comprovações, ao Departamento de Administração Acadêmica para preenchimento de requerimento. De posse da documentação o interessado desloca-se, em seguida, ao Serviço Geral de Comunicação e Arquivo para efetivar a abertura do processo. No setor, o interessado deposita a documentação e informa-se do número do respectivo processo.

O processo, após devidamente composto pelo Secom, é encaminhado ao DAA para conferência da documentação e posterior envio à unidade acadêmica responsável de acordo com o curso do discente. De posse do processo a unidade acadêmica realiza uma movimentação interna, repassando a documentação ao respectivo coordenador de curso ou ainda a um relator para análise, uma vez que o pleito deve ser apreciado e aprovado pelo respectivo colegiado do curso do aluno.

Após análise e julgamento da solicitação o processo retorna ao DAA para registro da decisão na evolução curricular do requerente no sistema acadêmico, quando deferido o pedido. Consolidado o resultado o DAA envia o processo ao Secom para efetivação do arquivamento. A documentação é mantida no setor durante determinado prazo e, posteriormente, encaminhada para o Arquivo Central da instituição.

Ressalta-se que o gerenciamento do processo, quando físico, possuía, em geral, burocracia nas fases de tramitação do processo, falta de celeridade no deslocamento do processo, dificuldade de acompanhamento das análises do processo por parte do interessado e despesa com material - como papel, impressão etc. - e com pessoal.

A implantação do processo eletrônico no Sipac contribuiu com relevantes benefícios quanto ao gerenciamento de processos na instituição - como a celeridade nas fases de análise dos processos administrativos, a preservação da integridade das informações dos 
processos administrativos, a economia de despesa com material e serviços entre outros. Entretanto, tratando-se de um sistema genérico, isto é, para os variados tipos de processos da instituição, o processo eletrônico do Sipac não oferece funcionalidades específicas para cada tipo de processo - o que, no caso do processo de aproveitamento de atividades complementares, poderia facilitar a análise e as decisões, como proposto pelo processo eletrônico do e-Acadêmico.

\section{Processo proposto}

O sistema e-Acadêmico de aproveitamento de atividades complementares possui um protótipo e encontra-se em fase de testes de funcionalidades no portal Admindcomp, com telas desde a abertura do processo até a possibilidade de seu arquivo - como a análise do processo, figura 4, diferencial por disponibilizar as informações do processo no estilo de linha do tempo, por meio da qual é possível visualizar todas as ocorrências registradas no processo de forma dinâmica e panorâmica.

Figura 4 -

Linha do tempo do processo.

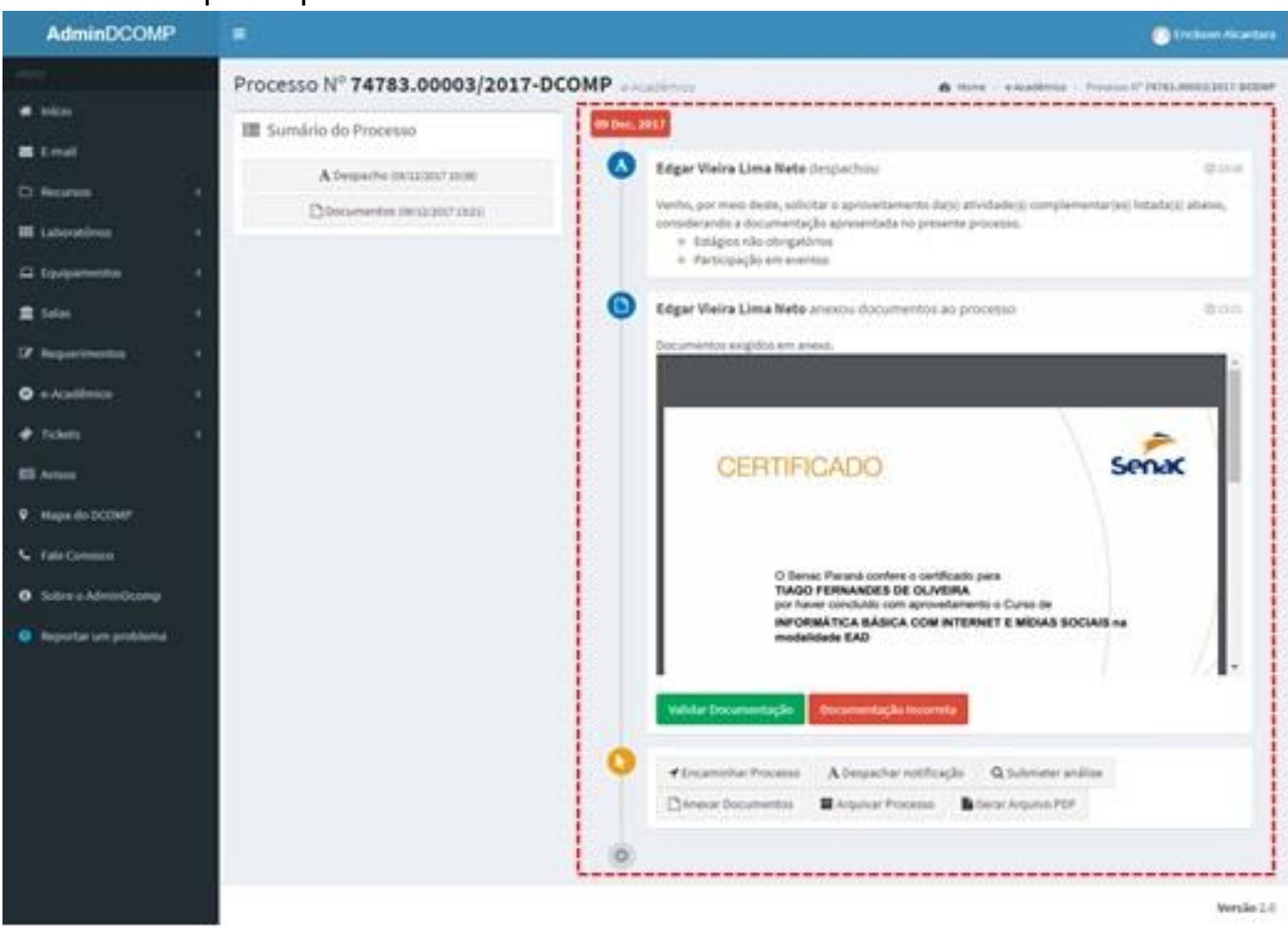

Fonte: Admindcomp (2018).

A criação do módulo do e-Acadêmico para o processo de atividades complementares considerou o fluxo de processo apresentado na figura 5, prevendo a participação de discentes, de servidores, de relatores e de coordenadores de curso e tornando o procedimento mais restrito à unidade acadêmica. 
Figura 5 -

Fluxo do processo de aproveitamento de atividades complementares.
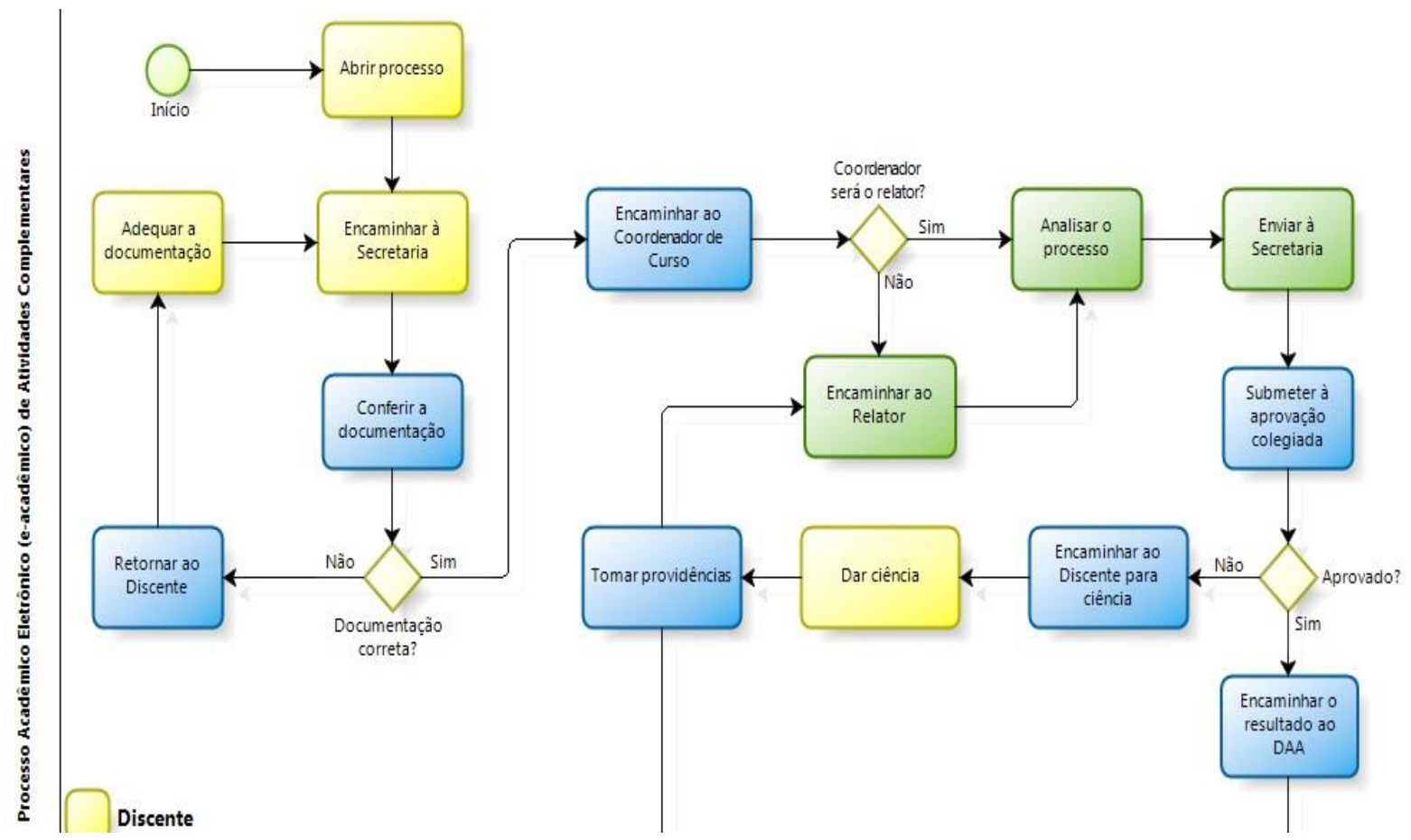

Fonte: autores (2019).

Como afirmam Laudon e Laudon (2007), uma nova solução de sistema de informação não é apenas uma questão de instalar hardware e software. É preciso lidar com as mudanças que a nova solução implicará e planejar benefícios e riscos possivelmente trazidos por sua implantação.

Os benefícios e riscos da propostas estão apresentados na figura 6 .

Figura 6 -

Benefícios e riscos.
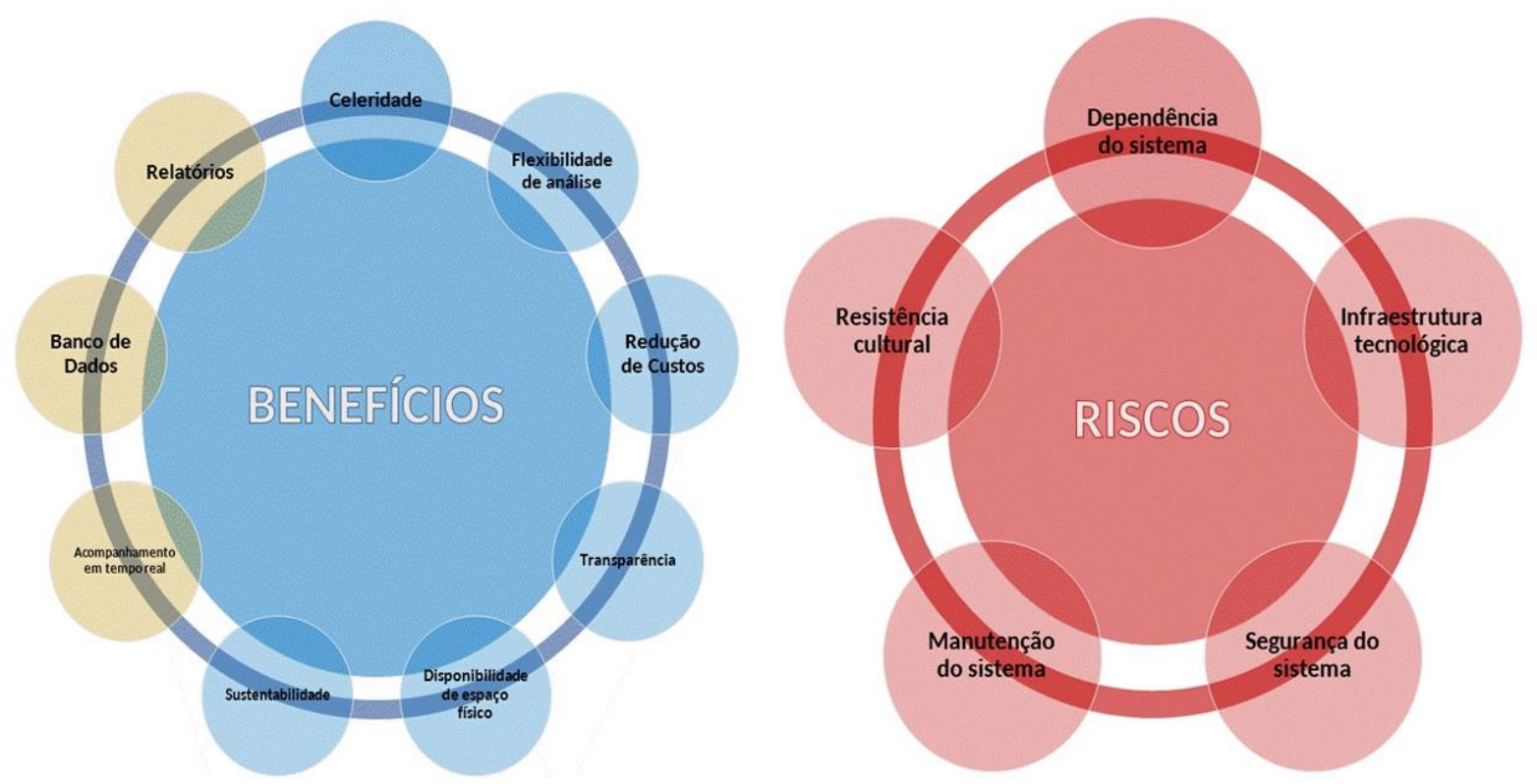

Fonte: autores (2019). 
De modo geral, no tocante a benefícios, o processo eletrônico tem como principal qualidade o aumento da celeridade no gerenciamento durante as fases do processo instauração, instrução, relatório e decisão (Cunha Junior, 2016). Ademais, com a possibilidade de acesso e análise em qualquer tempo e lugar, a implantação do processo eletrônico diminui consideravelmente o tempo de vida do processo, favorecendo tanto o requerente quanto a organização. Com base na escassez de recursos - financeiro, material, pessoal - a redução de custos torna-se outra importante vantagem da implantação do processo eletrônico. O processo eletrônico também coopera para maior transparência dos atos da administração pública, uma vez que as ações registradas nos autos podem ser acompanhadas em tempo real pelos envolvidos no processo. Com a eliminação do uso de papel, a implantação do processo eletrônico contribui para a redução da necessidade de espaços físicos para armazenamento dos processos e para uma administração mais sustentável.

Os benefícios elencados até aqui podem ser relacionados tanto ao processo eletrônico do Sipac quanto ao processo eletrônico do e-Acadêmico. Além desses, para o e-Acadêmico, podem-se ressaltar outros benefícios: permite que o interessado acompanhe integralmente as fases e análises dos autos, contribuindo para a celeridade de resposta do julgamento da solicitação; a criação de um banco de dados com os registros de análises realizadas anteriormente pode auxiliar em julgamentos coesos e lineares; o acesso a relatórios estatísticos da usabilidade do sistema também pode auxiliar a tomada de decisões para melhoria dos índices acadêmicos.

Quanto a riscos a utilização de um sistema de processo eletrônico torna o desenvolvimento das atividades laborais do órgão público dependente do sistema, podendo lidar com interrupções no serviço razões diversas, como quedas de energia ou falhas no sistema. Na UFS, no entanto, esse risco - mesmo antes da implantação do processo eletrônico do Sipac - já era uma realidade, uma vez que grande parte de seus procedimentos administrativos está vinculada diretamente ao uso dos portais de sistemas integrados.

A necessidade de obter uma infraestrutura tecnológica - como aquisição de servidores, microcomputadores, scanners - é uma demanda evidente nos órgãos para implantação do processo eletrônico. Para a implantação do e-Acadêmico, porém, essa dificuldade fica minimizada pelo fato de o sistema utilizar uma infraestrutura tecnológica já disponível na instituição. Ao longo do tempo, contudo, pode surgir a necessidade de uma melhor infraestrutura tecnológica para aportar o sistema.

Outra relevante questão acerca dos riscos diz respeito à segurança e à manutenção do sistema. Por conter significativas informações de usuários, a segurança do sistema - e de sua base de dados - é um item importante na implantação do processo eletrônico. Já a manutenção do sistema, tendo em vista a dificuldade de recurso pessoal adequado, também é uma preocupação considerável na aquisição de um sistema desse porte.

A implantação do processo eletrônico enfrenta também a resistência cultural devido à informatização de procedimentos. Nesse sentido, consciente de que qualquer mudança dessa grandeza possa trazer questionamentos e resistência de alguns envolvidos, preveem-se, junto à implantação do e-Acadêmico, no intuito de reduzir potencial aversão, a realização de capacitação presencial a interessados, de modo a demonstrar in loco o funcionamento do sistema, bem como a disponibilização de manual de instrução das 
funcionalidades do sistema, a fim de minimizar possíveis dificuldades no gerenciamento do processo por parte dos usuários. Ressalta-se que ambas as ações foram incorporadas à implantação do processo eletrônico do Sipac na instituição.

\section{Considerações finais}

Este estudo teve como propósito apresentar uma proposta de criação de processo acadêmico eletrônico de aproveitamento de atividades complementares no Departamento de Computação da Universidade Federal de Sergipe, visando, sobretudo, preencher espaços deixados pelo processo eletrônico implantado na instituição, como a padronização do procedimento da análise dos processos administrativos, a criação de um banco de dados com os registros de análises realizadas anteriormente, o acompanhamento integral das fases e análises do processo administrativo e a exportação de relatórios estatísticos acadêmicos, podendo, assim, contribuir diretamente com 0 atendimento à comunidade acadêmica.

A implantação do e-Acadêmico caminha no sentido de refletir melhorias na gestão administrativa da organização focal da pesquisa, acreditando obter melhor padronização do procedimento da análise dos processos administrativos; preservação da integridade das informações dos processos na organização focal; crescente eficiência, eficácia e efetividade da ação departamental; promoção de processos administrativos seguros, transparentes e econômicos; e ampliação da sustentabilidade ambiental com o uso da TIC em substituição da utilização de papel.

$\mathrm{Na}$ avaliação de documentos, considerando principalmente o banco de dados do próprio sistema, confia-se em oferecer maior celeridade na tramitação e nas fases de análise dos processos. Nesse sentido, tem-se a perspectiva, portanto, de que o estudo atingiu o objetivo proposto de possibilitar, a partir de uma plataforma eletrônica específica do processo acadêmico de atividades complementares, a possível melhoria de eficiência no gerenciamento de processo do Departamento de Computação.

Salienta-se que o e-Acadêmico, pela abordagem específica para o tipo de processo, não só apresentará um fluxo geral de determinado procedimento - como o processo eletrônico do Sipac -, mas também terá a capacidade de gerenciar todo o conteúdo nele produzido, sendo possível gerar relatórios, consultar gráficos e cruzar dados no tocante às solicitações de aproveitamento de atividades complementares da unidade acadêmica, contribuindo para a tomada decisões sustentadas em ocorrências devidamente comprovadas.

Nesse contexto, o e-Acadêmico cria parâmetros para novos estudos, tais como: a proposição de novos processos eletrônicos departamentais - como o processo de aproveitamento de componentes curriculares, que possui fluxo de procedimento similar ao tratado nesta pesquisa - no sentido de expandir as funcionalidades do sistema; a extensão do sistema para outras unidades acadêmicas, de modo a proporcionar a melhoria da gestão administrativa dos processos na instituição; a busca por formas de comunicação entre o e-Acadêmico e o processo eletrônico do Sipac, possibilitando a integração dos sistemas de processos da UFS; a melhoria do sistema de processo eletrônico do Sipac, de maneira que seja possível a implementação das funcionalidades 
contempladas pelo e-Acadêmico; a elaboração de pesquisa baseada em nova metodologia sem a participação do pesquisador, com intuito de verificar a efetividade do sistema de processo eletrônico do Sipac na instituição, de modo a perceber o atendimento completo das necessidades das unidades acadêmicas.

\section{Referências}

ABRÃO, Carlos Henrique. Processo eletrônico. Revista eletrônica [do] Tribunal Regional do Trabalho da 9a Região, Curitiba, v. 2, n. 15, 2013, p. 53-62. Disponível em: https://juslaboris.tst.jus.br/handle/20.500.12178/87251. Acesso em: 14 fev. 2019.

ADMINDCOMP. Portal administrativo do departamento de computação. Disponível em: http://www.admin.dcomp.ufs.br. Acesso em: 18 nov. 2018.

MELLO, Celso Antônio Bandeira de. Curso de direito administrativo. São Paulo: Malheiros, 2015.

BRASIL. Decreto n. 8.539, de 8 de outubro de 2015. Dispõe sobre o uso do meio eletrônico para a realização do processo administrativo no âmbito dos órgãos e das entidades da administração pública federal direta, autárquica e fundacional. Brasília: DOU, 2015. Disponível em http://www.planalto.gov.br/ccivil_03/_Ato20152018/2015/Decreto/D8539.htm. Acesso em 12 set. 2018.

CARVALHO FILHO, José dos Santos. Manual de direito administrativo. São Paulo: Atlas, 2015.

CORRÊA, Davi Beltrão de Rossiter. Processo administrativo eletrônico. Revista Jus Navigandi, Teresina, ano 16, n. 2850, 2011, s/p. Disponível em https://jus.com.br/artigos/18959. Acesso em 14 jul. 2018.

CRESWELL, John W. Projeto de pesquisa: métodos qualitativo, quantitativo e misto. Porto Alegre: Bookman, 2010.

CUNHA JÚNIOR, Dirley da. Curso de direito administrativo. Salvador: Juspodivm, 2016.

DI PIETRO, Maria Sylvia Zanella. Direito administrativo. São Paulo: Atlas, 2010.

ELIAS, Ezmir Dippe. Gerenciamento eletrônico de documentos (GED): aplicação na Universidade Federal de Santa Catarina. Ágora, Florianópolis, v. 22, n. 45, 2012, p. 15-30.

ENAP. e-Processo: processo administrativo digital. Disponível em http://repositorio.enap.gov.br/handle/1/377. Acesso em 14 jul. 2018.

EUROPEAN COMMISSION. The european eGovernment action plan 2011-2015: harnessing ICT to promote smart, sustainable \& innovative Government. Brussels: EC, 2010.

FELIX, Aliny; SILVA, Edson Rosa Gomes da. A gestão documental como suporte ao governo eletrônico: caso da Secretaria de Estado da Saúde de Santa Catarina (SES/SC). Revista Democracia Digital e Governo Eletrônico, Florianópolis, v. 1, n. 2, 2010, p. 36-50.

FORNARI JUNIOR, Celso Carlino Maria. Aplicação da ferramenta da qualidade (Diagrama de Ishikawa) e do PDCA no desenvolvimento de pesquisa para a reutilização dos resíduos sólidos de coco verde. Revista INGEPRO - Inovação, Gestão e Produção, v. 2, n. 9, 2010, p. 104-112.

GERHARDT, Tatiana Engel; SILVEIRA, Denise Tolfo (org.). Métodos de pesquisa. Porto Alegre: Ufrgs, 2009.

GIL, Antônio Carlos. Como elaborar projetos de pesquisa. 4. ed. São Paulo: Atlas, 2002. 
LAUDON, Kenneth C; LAUDON, Jane P. Sistemas de informação gerenciais. São Paulo: Pearson Prentice Hall, 2007.

MARCONI, Marina de Andrade; LAKATOS, Eva Maria. Fundamentos da metodologia científica. São Paulo: Atlas, 2010.

MEIRELLES, Hely Lopes. Direito administrativo brasileiro. São Paulo: Malheiros, 2010.

MORAES, Fausto Cruzeiro de. Processo administrativo eletrônico: plano de implantação na Controladoria Geral do Estado de Goiás. Goiânia: UFG, 2016. 127f. Dissertação (Mestrado em Administração). Programa de Pós-Graduação em Administração, Universidade Federal de Goiás

PRODANOV, Cleber Cristiano; FREITAS, Ernani Cesar de. Metodologia do trabalho científico: métodos e técnicas da pesquisa e do trabalho acadêmico. Novo Hamburgo: Feevale, 2013.

SILVA, Sidney Verginio da; PORTUGAL, Nilton dos Santos. O gerenciamento eletrônico de documentos aplicado à gestão documental docente de uma instituição de ensino superior no sul de Minas Gerais. Revista Gestão \& Tecnologia, Pedro Leopoldo, v. 16, n. 1, 2016, p. 254-271.

SOUZA, Jacqueline de; KANTORSKI, Luciane Prado; LUIS, Margarita Antonia Villar. Análise documental e observação participante na pesquisa em saúde mental. Revista Baiana de Enfermagem, Salvador, v. 25, n. 2, 2011, p. 221-228.

UFS. Resolução $n$. 14, de 24 de abril de 2015. Aprova alterações nas Normas do Sistema Acadêmico de Graduação da Universidade Federal de Sergipe. São Cristóvão: UFS, 2015.

UFS. UFS em números 2017. Disponível em https://goo.gl/UBHJUD. Acesso em 23 fev. 2018.

Erickson Santos de Alcântara é assessor técnico do Centro de Ciências Exatas e Tecnologia da Universidade Federal de Sergipe.

Orcid: https://orcid.org/0000-0002-6517-4795.

Endereço: Avenida Marechal Rondon, s/n - 49100-000 - São Cristóvão - SE - Brasil.

E-mail: erickson@ufs.br.

Maria Conceição Melo Silva Luft é professora no Departamento de Administração da Universidade Federal de Sergipe.

Orcid: https://orcid.org/0000-0003-2713-2700.

Endereço: Avenida Marechal Rondon, s/n - 49100-000 - São Cristóvão - SE - Brasil.

E-mail: ceica@infonet.com.br.

Thais Ettinger Oliveira Salgado é professora na Universidade Federal de Sergipe.

Orcid: https://orcid.org/0000-0001-7559-2790.

Endereço: Avenida Marechal Rondon, s/n - 49100-000 - São Cristóvão - SE - Brasil.

E-mail: thaisettufs@gmail.com. 
Kleber Fernandes de Oliveira é professor na Universidade Federal de Sergipe.

Orcid: https://orcid.org/0000-0001-6568-6240.

Endereço: Avenida Marechal Rondon, s/n - 49100-000 - São Cristóvão - SE - Brasil.

E-mail: kleber.ufs@hotmail.com.

Recebido em 3 de fevereiro de 2020.

Aceito em 19 de abril de 2020.

(c) (i) 